\title{
Papers
}

Explorations into Children's Literature

\section{Parent, Child and State in Chinese Children's Books}

\author{
Lijun Bi, Xiangshu Fang and Clare Bradford
}

A marked characteristic of Chinese society is its alertness to hierarchical differences and its expectation of obedience to proper authority. From the Confucian point of view, tranquillity and happiness within society can only be achieved through xiao (filial piety), the principal value of Confucian morality. Filial piety is also central to the Confucian rationale for organising social order, revolving around conceptions of superior-inferior status in human relationships: children ought to obey parents, wives ought to obey husbands, and subjects ought to obey their emperor. The prevalence of such indoctrination in Chinese children's books can be traced to the Confucian belief that children are able to reach their full potential sense of benevolence by imitating the proper behaviour of their elders and role models in books. Indeed, the political role of the moral training in books worked effectively following the adoption of Confucianism as the state doctrine around $100 \mathrm{BC}$, and helped to maintain dynastic reign for about two thousand years, until Western warships and guns shattered Chinese confidence in Confucianism in the late nineteenth century.

Attempting to strengthen China's global position, leading figures of the Chinese literati as well as Manchu rulers began a reform movement, imitating Western institutions. The government began to send students overseas. These students became leaders of a new cultural movement in the early twentieth century. Hu Shi, Zhou Zuoren and Lu Xun, who had spent years studying in the United States or Japan, advocated Western, child-centred education theories which recognised children as independent human beings, entitled to their own rights, as opposed to being subjected to what they regarded as the spiritual lethargy derived from the Confucian cult of ritualised subordination. A shift in values accompanied the advent of 
revolutionary beliefs, shaping modern Chinese children's literature for the first half of the twentieth century. ${ }^{1}$

In Mao's China, the interests of individuals were embraced as part of the interests of the community as a whole. The rhetoric of revolution became a dominant trait of the literature of this era, while the dominance of communitarian over individual identities turned out to be its central concern. The influence of parents and family were often critiqued in terms of social class background. As reflected in many children's stories produced in that period, children were no longer viewed as heirs to the family, but rather to the new socialist motherland and the proletarian revolutionary cause. Stories written in those years are often readily seen, in their political context, as propaganda.

After the crackdown on the 1989 students' pro-democracy movement, a new ideological system of Neo-Confucianism began to take its shape, filling the vacuum left by the decline of faith in Marxism in China. Chinese moral educators asserted that modernisation did not necessarily mean Westernisation. They argued that Confucianism was not an obstacle to China's development, as preached by the intellectuals of the early twentieth century and Maoist ideologues, and could actually be conducive to modernisation. From the early 1990s, however, a small group of young authors of juvenile fiction took a quite radical turn, characterised by an anti-establishment stance, challenging both the Confucian and Communist representation of parent-child relationship in their works.

$\mathrm{Xu} \mathrm{Xu}$ argues in her study of Sparkling Red Star that 'the production of an agential child is intricately intertwined with the nation-building projects of the People’s Republic of China' and 'should be understood as culturally and historically produced' (Xu 2011, p. 382). Very little research exists on the changing representations of parent-child relationships in Chinese children's books that were driven by political changes. This paper seeks to fill the gap by identifying and documenting these changing representations in four distinctive periods: the pre-modern dynastic period to 1911; the Republican and Nationalist phase from 1911 to 1949; the phase of Mao’s socialism from 1949 to 1976; and the post-Mao phase from 1976 to 2000. We argue that the educational impetus of Chinese children's texts dealing with parentchild relationships derives from the abiding force to strengthen the rule of the state in different historical contexts. We further argue that the openly didactic nature of these texts stems from the pragmatic goal of China's rulers to maintain control of the education system 
in order to enable political indoctrination and moral cultivation. This paper adds a new dimension to the continuing discussion on the transformative potential of children's literature (Rudd 2004; Mickenberg 2006; Reynolds 2007; Gubar 2009; Bernstein 2011; Xu 2011).

\section{The pre-modern dynastic period to 1911}

The rationale of Confucianism for organising social hierarchy begins with the ancient yinyang cosmic order and the perception of a natural pecking order of superior-inferior relationships. Parents are superior to children, men to women, and rulers to subjects. The traditional term in the Chinese language for government officials representing the ruler is fumuguan [parent-official], and the term for the ruled, zimin (child-people). Chinese people, thoroughly habituated to the family system, accept the government of the state as homologous with the hierarchical system within the family, referring to the state as guojia (state family or family state). State rule is regarded as just as natural as the parent-child relationship.

In Chinese history, disobedient offspring were regarded with particular revulsion, and there are numerous cases of undutiful grown-up children being thrown down wells to their deaths by angry relatives. Such a demanding concept of family and social discipline may help to explain why the lack of individualism and the veneration of conformity have been a continuous feature of Chinese culture (Lynch 1996). According to one of the world's oldest texts expressly created for children, Qian zi wen (An Essay of A Thousand Characters) written one thousand five hundred years ago, which became a compulsory textbook for Chinese children in the tenth century (Wang Longlin \& Zhang Yanfu 1995), there are specific requirements for applying moral principles in relationships between father and son as well as sovereign and subject:

To subordinate oneself to father and to serve the emperor is to show reverence and respect, and a person has to exert his utmost strength to show filial piety towards parents and even sacrifice his life to prove loyalty to his emperor.

(Wu Meng 1991, p. 124)²

On one occasion, when questioned about what exactly filial piety entailed, Confucius said, 'not being disobedient.' He further explained that 'parents, when alive, should be served according to propriety; that, when dead, they should be buried according to propriety; and 
that they should be offered sacrifice according to propriety.' He complained, 'the filial piety of now-a-days means the support of one's parents. But to keep dogs and horses likewise needs something in the way of support; - without reverence, what is there to distinguish the one support given from the other? ... the difficulty is the countenance' (trans. Legge 1971, pp. 147-48). An Essay of A Thousand Characters uses vivid metaphors to illustrate such reverence:

As if treading on the brink of a deep gulf or on thin ice,

a filial son has to be apprehensive and cautious,

taking every detail in looking after parents, such as

their getting up in the morning; going to bed in the evening,

whether they are warm enough in winter or cool in summer.

(Wu Meng, p. 124)

San zi jing (The Three Character Classic), written about eight hundred years ago, was another major primer in the dynastic period. Although specifically for children, it also outlines the duty of parents in terms of educating the young:

People, at beginning,

have good nature.

Comparable characters become

altered through learning.

With no teaching

character drifts downwards.

The teaching method

values total devotion.

Mother of Mencius

selected residential locality.

Son didn’t study;

mother cut cloth.

(cited in Fang 2003, p. 18)

Confucians believe that all people are good by nature, and that environment and education either help children maintain this good nature and further develop the potential of their innate 
moral sense, or else they fall astray. This text primarily emphasises the role of the mother in moral education and character formation: the most crucial factor in teaching children morally lies in the mother's total devotion. According to an expert in Confucianism, Zhang Taiyan (Wu Meng, pp. 7-8), this total devotion starts with taijiao (prenatal education), which can be summarised by a single word, zheng (upright), involving even physical application. Zhang Taiyan explains that, from the Confucian point of view, a pregnant woman should not sleep on her side, lean on her side while sitting, or stand with her weight on one foot. The most important factor when pregnant is what she sees and hears. She should try her best to avoid seeing uncanny things or hearing licentious sounds. The next important step to teach children is when they begin to eat solid food. They should use chopsticks with their right (as against their left) hand. When boys begin to learn to talk, the mother must avoid using a sweet girlish voice. This is also the time to teach boys to respond quickly when spoken to and for girls a gentle answer is encouraged. At the age of seven, boys and girls should not sit on the same mat, or drink from the same cup. At eight, they should learn to respect the senior: let the senior enter or leave first, offer seat to the senior and start to eat only when the senior starts. Children's proper manners are the result of the mother's proper influence.

When children are able to walk around, the locality of the residence or the neighbourhood begins to have an impact on their moral growth. The first of many examples in The Three Character Classic illustrating this is that of the mother of a Confucian sage, Mencius. At first the son and mother lived near a graveyard. A young Mencius, for fun, imitated the crying of the mourning people. His mother decided that this place was not conducive to his development. They moved to a busy town and soon found themselves near a slaughter house. Mencius took great interest in slaughtering. His mother decided to move again. This time they moved to a place close to the temple of Confucius, where government officials often came to salute the sage by bowing and kowtowing, according to the rules of propriety. Mencius came back to tell his mother that he would follow Confucius's suit, and the mother felt happy to have found such a good place to live.

However, the right environment alone cannot ensure the proper growth of children: education, too, has a vital role. Mencius became a student of $\mathrm{Zi} \mathrm{Si}$, one of Confucius's disciples. One day Mencius felt tired and came home early. His mother was weaving cloth on a loom. He told her the study was boring. She was most upset and cut the cloth on the loom. Mencius was alarmed, knelt down and asked why. His mother replied, 'Your study is like my 
weaving cloth. I have to weave inch by inch till eventually the cloth becomes long enough to be of any use. I cut the cloth to show you that once it is cut, all the efforts of the past are just wasted and it will never be of any use.' (Wu Meng, p. 9). It is this kind of influence from his mother that led Mencius in the end to become the most famous Confucian sage after Confucius himself.

The application of filial piety is a life commitment. The children's book Ershisi xiao tu (Twenty-four Stories of Filial Piety with Illustrations), compiled about eight hundred years ago, incorporates an example of such commitment:

A filial son, who was seventy years old himself, was dressed in colourful clothes and then poured water on the ground. He began to walk like a toddler, pretended to slip on the ground, and had a big fall. Then he imitated the crying of a baby. All this was for entertaining his sick parents.

(cited in Fang, p. 17)

The application of filial piety is expected to extend in a horizontal direction outside the immediate family to relatives, the clan, and finally to senior members of society and the state.

\section{The Republican and Nationalist phase, 1911 to 1949}

Although the state as a central authority was weak during this turbulent era when various political forces vied for power, it is this period that witnessed the rise of Chinese nationalism, marked by the advent of a wave of new revolutionary ideas in the May Fourth new culture movement, an outcome of the sustained resentment among patriotic Chinese intellectuals against imperialist occupiers, Japan in particular. The best intellectual minds of the time turned to a new area, children's education, hoping that the new generation would eventually shoulder the task of building a new China. A great deal of literature was created specifically for children, in which a new parent-child relationship was constructed. In these works, the influence of the state as a ruler weakens, but the fate of the nation becomes the central concern. For example, in the story Bai qizi (White Flags) by Cheng Sheng, published in Weekly Review on May 26 1919, three weeks after the students' May $4^{\text {th }}$ patriotic demonstrations, five characters are depicted to represent 'typical' attitudes of that time. Erer and his big brother are portrayed as children with an innate sense of righteousness, both having a clear-sighted outlook as to what was right or wrong for the nation. Both characters 
are supportive of older students who took part in the demonstration at Tiananmen. These two boys, a primary school pupil and a secondary school student, are thus positive characters who represent the future and are the hope of the nation. Contrastingly, their father, a government official, is negatively depicted as someone who represents a 'heartless and shameless traitor'. The mother and the house servant are reflective of the 'ignorant' and indifferent majority of the Chinese population: people who felt that the demonstration at Tiananmen or the threat of the nation's extinction had nothing to do with them. Stories like this ironically affirm the traditional Confucian notion of political-moral training for the common good, but in a way it is a chronological reversal of Confucianism, because in this political ideology, Chinese youth were to lead and educate their elders, and children to instruct their parents (Bi 2008, p. 4).

The veneration of maternal love as a social remedy is strongly advocated by Bing Xin, arguably China's most renowned children's author of the twentieth century. In the first major work of modern Chinese children's literature, Ji xiaoduzhe (To Young Readers) (1926), she writes:

Maternal love is unconditional. A mother's love can disregard everything and erase everything yet it envelops me in layers, making me what I am today. I am loved for nothing but myself. My mother's love towards me, yours towards you, his mother's love, her mother's ... all are the same. There is never any shortage in width, length, height or depth.... maternal love is eternal. My mother loves my body as well as my soul. She loves my front, back, left and right. She loves my past, my present, and my future. Her love would not change a bit, even if everything else in the world was destroyed....

Her love not only surrounds me, but also surrounds all those who love me. Because she loves me, she also loves all the children in the world, and she loves all the mothers even more. Little friends, let me tell you the truth which is very simple to children, yet very profound to grown-ups: 'The world has been built in this way!' (Letter No. 10)

Bing Xin's 'maternal love' is somewhat reminiscent of the Confucian notion of filial piety in terms of the natural bond between parents and children. In this new relationship, the mother, more than the father, is totally devoted to ensuring the continuity of life. However, this results from her instinct to protect the young and her desire for a better environment for the next 
generation, whereas the traditional relationship was in contrast based on the notions of debt and repayment, guidance and obedience, and control and passivity. The idea of a universal 'maternal love' is strongly opposed by Marxism-influenced revolutionary writers.

The attitudes of the parents in stories created by revolutionary writers differ, reflecting their different social class backgrounds. In Lu Yin’s story (1926), Liang ge xiao xuesheng (Two Pupils), the descriptions of the house with its 'shining red painted gate', the food Guoshu's mother prepared for him, 'delicious orange-coloured cake and apples as red as lip stick' and the well maintained school with 'white walls and a shining black gate' all appear to imply that the family was quite well off. Guoshu's father does not believe that student demonstration would achieve anything, but allows the child to attend the demonstration because, in his eyes, 'it's a good opportunity for him to go out and face the real world.' This description strongly implies that Guoshu is protected in a privileged environment away from 'the real world', and that this concerns his father. Indeed, Lu Yin's work reflects her own family background and her wish to encourage children of wealthy families to break away from the protection of their parents to engage actively in the grand social transformation. Dai Pingwang, who later became a member of the League of the Left-wing Writers, strongly advocated 'revolutionary literature'. In his story of Xiao Feng (1928), the main character is from a railway worker's family, who cannot afford to send him to a regular school so that he attends only an evening school for workers' children. Xiao Feng's father is described as 'smelling like the railway', which 'was as familiar to Xiao Feng as home'. Xiao Feng's father is portrayed not only as a whole-hearted supporter of the patriotic demonstrations but also as a keen participant and an organiser of subsequent strikes.

Remarkably, the traditional power holder of the patriarchal family, the father, is still depicted in these revolutionary stories as exercising decision-making power in regard to granting permission for their children to participate in demonstrations, whilst mothers are always portrayed as 'protective' and discouraging their children's integration into a larger community beyond the family. All the main characters are boys in the stories discussed here as well as those of a wider authorship that deal with patriotic demonstrations. In other words, these stories present an overwhelming male dominance in participation in the political activities concerning the fate of the nation. These boys are shown as interacting with other boys at school and adopting values from some older boys, who are presented as selfconscious ideologists, always ready to provide patriotic slogans. This over-representation of 
male participants in patriotic demonstrations provides some indication of these authors' stereotyped views in terms of gender roles in relation to family, society and political participation.

\section{The phase of Mao's socialism, 1949 to 1976}

On the eve of the founding of the People's Republic of China in 1949, the chairman of the Chinese Communist Party (CCP), Mao Zedong said, 'To win the country-wide victory is only the first step of a long march of ten thousand li.... The Chinese revolution is great, but the road after the revolution will be longer, the work greater and more arduous.' (Mao Zedong 1949/1966, p. 193). The newly established People's Republic had a tremendous task in consolidating its power. It had to construct a national economy shattered by both World War II and the subsequent civil war. It had to build up a strong defence against what was regarded as the American threat, especially after the Korean War in the early 1950s. The task was inextricably linked with the task of training revolutionary constructors and defenders, and children's books assumed an important role in this training. China's traditional ancestral reverence, family-clan cohesiveness and filial piety had long been eroding, and the Communist victory furthered the process. In various campaigns of the 1950s, children were praised for denouncing their 'backward' parents, thus spectacularly reversing the ancient stress on filial piety as the highest virtue. Family ties were ridiculed as 'feudal', leaving individuals, devoid of family support, at the mercy of the state authorities (Fairbank 1976, pp. 375-76).

Authors of children's literature were obliged to create stories to praise young people, especially those with education, for criticising the 'traditional feudalistic ideas' of the older generations of parents and grandparents, which were shown to hinder the social progress of the communists. Of many similar works, Ma Feng's 1954 story, Han Meimei, is a good example. Han Meimei, a seventeen-year-old girl, does not do well in the entrance examination for the senior high school. Her family is saddened by the news. For generations they have been illiterate peasants and they all hope that Han Meimei, the only child of the family, will be capable, through education, of gaining the opportunity to earn good money from which the whole family might benefit. Han Meimei's unsuccessful performance in the entrance examination makes her mother sigh constantly. Her grandmother can't help disclosing what she has always felt: 'What could you expect of a girl? What a waste it was to send a girl to school for all these years!' Her father is described as most upset. He throws the 
rice bowl on the table, calling her 'useless', 'a failure' and 'a disgrace to the family'. But Han Meimei is depicted as believing firmly that she can nonetheless contribute to the motherland by participating in its agricultural work. The story demonstrates that Han Meimei's new scientific farming not only boosts the output of the village but also greatly increases her family income. At the end of the story, Han Meimei's father has to admit that he has been wrong and the new socialist values of the younger generation are the only way to bolster the interests of the family and the community.

Both the class nature of family and the ideological battle between public interests and private are more clearly identified in the story Duiyuan de daolu (The Road of a Young Pioneer Member) written by Cui Daoyi in 1956. This is a story about two fourteen-year-old boys, Fang Cheng and Yang Wenbao, from very different families. Fang Cheng's father is described as a People’s Liberation Army officer, fighting against American imperialists in Korea and his mother, a member of the CCP as well. Since Fang Cheng is from such a revolutionary family, he is shown as naturally progressing very fast, and as soon as he reaches fourteen, his application for the Communist Youth League membership is approved in no time. Yang Wenbao feels himself to be far inferior to Fang Cheng: his father is an owner of a music instrument shop, and therefore 'a capitalist, who, not a big one though, makes a living by exploiting other people’, according to Yang Wenbao himself (p. 132). Further, his mother, also according to Yang Wenbao himself, 'is full of bourgeois ideas. Her parents are rich peasants.' The story tells how Fang Cheng, a representative of the proletarian ideology, helps Yang Wenbao, a child badly influenced by his parents' class ideas. With the help of Fang Cheng, Yang Wenbao finally joins the Youth League. In this new socialist society, terms like 'home' and 'family' are given a new meaning, such as when Yang Wenbao’s big sister, who has left home years ago to join the revolution, urges him, 'Grow up quickly, so you can join the Communist Party, and the Party is our real home, and the comrades there are our real family members.' Yang Wenbao feels that 'I must let Mum and Dad know that I am not going to be the son of a capitalist, but a revolutionary youth.' The story is an example of Mao's widely publicised view, which emphasises the importance of education in shaping children's new socialist values, regardless of their family class background. 
The reality, however, was quite different in regard to family class background. June Dreyer notes that in Mao's China class labels were assigned to everyone 'with a certain amount of arbitrariness’ (Dreyer 2010, p. 87). ‘To make matters worse', Dreyer writes:

[C]lass labels were not only assigned for life, they were hereditary. This caused problems when the children of bad class wished to get married, apply for jobs, or seek educational opportunities. Such hereditary designations cannot be considered Marxist.... Hereditary class designations were decidedly anti-modern - in fact feudal. (p. 87)

Jung Chang, the author of Wilde Swans and a former Red Guard, observes that by the end of Mao's rule China had become 'a moral wasteland and a land of hatred', and that Mao 'left behind not only a brutalized nation, but also an ugly land with little of its past glory remaining or appreciated' (Chang 1992, p. 659). Every child was singing: 'Father is close, mother is close, but neither is as close as Chairman Mao' (p. 339). Since children were regarded not as heirs to the family but to the proletarian revolutionary cause, children's biological parents were replaced by the nation-father Mao Zedong.

\section{The post-Mao phase, 1976 to 2000}

After Mao's death in 1976, the new leadership headed by Deng Xiaoping attempted to end the disorder caused by the Cultural Revolution. 'Patriotism' became the only explicit political message that had the consistent blessing of the children's book market. For instance, the poem Mama de ai [Mum’s love], written by Liu Binjun (1982), describes the love between mother and child. But at the end of the poem, the love is extended to the love of the motherland:

In a very hot night,

I woke up to see

Mum fanning me,

and herself sweating all through.

Mum's love is like the cool breeze.

One very cold rainy day,

Mum came to pick me up from school. 
The only umbrella covered me

and Mum herself was mostly in the rain.

Mum's love is like an umbrella.

Once, I was ill,

Mum took me to hospital.

Feeling my feverish forehead,

Mum's tears began to roll down her cheeks.

Mum's love is like tears.

One day, I broke a thermos, and told Mum a lie about it.

Mum's criticism made my face blush, and I lowered my head, daring not to look at her.

Mum's love is like the strict look on her face.

Once for homework, I had to make a sentence with 'most'.

I wrote, 'I love Mum most.'

But Mum said, 'The most lovable has to be the motherland, because she is the Mum for all of us.'

(cited in Fang, pp. 15-16)

The most significant publication for children' political-moral education in the 1990s was Xin san zi jing (The New Three Character Classic). According to its Compilation Committee (1994, p. 1), this text was written by a committee of fourteen experts, including scholars, educators, ideology workers, propagandists, and workers for the 'spiritual civilisation' 'through wide-range consultations and repeated discussions'. After almost an entire century, the Chinese Communist government finally recognised the effectiveness of the Confucian classics as a pedagogic tool for moral-political education, especially after the 1989 students' pro-democracy movement, in which young people revealed absolute contempt for state authority. The New Three Character Classic attempts to indoctrinate the young with NeoConfucian patriotism: 


\begin{abstract}
A young pupil
should show respect

to senior generations,

and practice etiquette.
\end{abstract}

Filial piety and fraternal submission

must pass on.

Relation between old and young

is like bone and flesh.

Bringing up children

is hard work.

One must repay

the kindness of parents

who care for their young

like the sun with seedlings.

When parents instruct,

children listen attentively,

and correct mistakes

with no hesitation.

Family love me

and I love family.

Extend this love

to our China.

(pp. 12-19)

The state, once again, has resumed its role as the absolute moral authority to regulate human relationships in children's books. The moral value of 'filial piety' and 'fraternal submission' are restored to the core position, which becomes the basis of 'patriotism'.

Not to be forgotten, however, are a small group of young authors of juvenile fiction, who took a quite radical turn after the crackdown on the 1989 students' pro-democracy movement, challenging the conventional representation of parent-child relationship in their works. Widely acclaimed by Chinese critics as one of the best in the genre of avant-garde juvenile 
fiction in the 1990s, Zai xiyuzhong huhan (Cries in the Drizzle), Yu Hua's debut novel (1993), depicts a family life in rural China under Mao’s rule. The narrator, Sun Guanglin, is the second son of the family. He is given up for adoption at the age of six to live with adoptive parents for over five years. At the age of twelve, he returns to his biological parents after tragedy befalls his adoptive family. The same night that he returns, the family house burns down to the ground. The coincidence makes his superstitious parents, brothers and indeed all the villagers believe that he is a kind of jinx. His status as an outcast places him in a unique position to observe the relations among his family members and among villagers.

The description of his birth is quite revealing in regard to the relationship between his parents. His mother is shown to deliver the child all by herself, 'just like a labouring female animal'. Immediately after the birth, she has to take food to her husband, who is toiling in the farming field. 'You want to starve me to death, don’t you?' he yells at her. 'Sorry for being late,' she has to apologise, 'but I was labouring and giving birth to a child.' Only then does he notice that her body looks different. She goes on to explain that, after the delivery, she has had to wash the baby, but not interested in any of these details, he impatiently interrupts her, asking 'Is it a boy or a girl?' 'A boy,' she replies. Sun Guanglin often feels that the creation of his life has been the result of his father's ugly behaviour; he will not wait for half a minute when he wants sex, pushing Sun Guanglin's mother down roughly and forcing sex on her instantly, just like an animal mating.

The complexity of the father-son relationship dominates the undercurrent of the novel, with no explanation offered as to why the father hates the son so much, and why the son is considered a degenerate and embarrassment by the father, who decides to give him up at six for adoption. Again and again, Sun Guanglin hears his father talk to neighbours that 'it would be wonderful if we didn't have that son of a bitch.' The novel captures the vulgar and despicable life of Sun Guanglin's father, who has absolutely no qualm about using the most beautiful words to conceal his selfishness, shamelessness, brutality and hypocrisy. He constantly lectures Sun Guanglin about the importance of protecting the reputation of the family, meanwhile trying to sleep with as many women in the village as possible. He even attempts to rape his daughter-in-law, Sun Guanglin's elder brother's wife. In Cries in the Drizzle, at least six other such father-son duos in the village are described through the eyes of the narrator or through a montage of events. Yu Hua's novel is only one of many similar works in the early 1990s that bitterly attack the father. The significance of such an attack has 
to be understood in its historical and political context. In 1989 the state launched a brutal crackdown on pro-democracy movements, killing hundreds, if not thousands, of young lives, and then almost immediately it instigated a patriotism education campaign, in which the country of China was constantly referred as 'the motherland', and patriotism was described as natural as the 'love' of child for mother. Regarded by Chinese critics as a representative of avant-garde works of the 1990s, Yu Hua's novel does not challenge the notion that one's country is one's mother, and indeed the image of an abused and humiliated mother in his novel is symbolic of China. The avant-gardism of the novel lies in its loud protest against patriarchal authority - be that of the father or the Party boss - who, morally, has already become bankrupt.

\section{Conclusion}

Chinese children's books are very distinctive in that they always promote strong political and moral content, due to the belief of Chinese writers of children's books that the primary function of their work is to train children in relation to such issues. Writers, Confucian or Communist, consider themselves as the vanguard of society with a social responsibility to educate the young. In dynastic China, the individual was subordinated to his or her family group. The empire was conceived as a family writ large, with the emperor as the father, who was supposed to rule according the Confucian moral principle of benevolence.

When the foundations of China were in crisis in the early twentieth century, with the degeneration of the traditional doctrine of Confucianism, elite intellectuals turned to the West for ideological remedies. Modern Chinese children's literature was produced by patriotic writers for the purpose of educating the future generation, so that 'saving the children' and 'saving China' became synonymous. In stories created during the May Fourth new culture movement, we can see how the children are represented as symbolic of the hope of the nation. These children appear to understand the importance of fighting against external aggression and internal weakness and the words spoken by them to their parents are not so much the words of a child to its parent, but are a form of moral instruction delivered by a young patriot to an ignorant older person. In Mao’s China, the Confucian idea of filial piety was regarded as feudal, and idealistic 'maternal love' as bourgeois, because they were both viewed as ignoring the class nature of family. In this paradigm, Chinese writers perceived Chinese society as an arena of class struggle. They defined their characters solely in terms of the individual's socially meaningful acts and intentions, which depended on their class. The 
main characters in children's stories were children, but they talked and behaved like adults or, more precisely, like Communist ideological and political instructors. These youngsters articulated all the abstract and artificial Maoist rhetoric of the time. The authors of these stories tried to assure young readers that in the big warm socialist family, everyone helped each other and nobody was allowed to be left behind.

The current Chinese adaptation of Confucianism recognises the importance of the role of filial piety, re-adopting it as the base for other moral qualities. Promoted in the 1990s, NeoConfucianism stresses that the notion of loyalty stems from the idea of filial piety, which is demonstrated in the individual's ultimate responsibility and duty to the nation, carried out through faithfully implementing the instructions of the ruling group. However, the fundamental difference between traditional Confucianism and Neo-Confucianism is that the traditional construction of children's moral character derives from a long-term value-oriented ideology, which aims at achieving a tranquil and happy world of benevolence, whereas the contemporary form aims at strengthening the subject-sovereign relationship by regulating the parent-child relationship. This reveals the short-term and expedient nature of this modern ideology as a strategy for ensuring the political survival of the ruling group. Overall it seems that the prevailing contemporary moral principles for children are only an impoverished residue of past ideologies, with an emphasis on the unquestioning trust of authorities as the dominant element. The moral authority of the state, however, is facing some serious challenge, as attested in Cries in the Drizzle: China's new generation of authors are refusing to be the mouthpiece for the state and are disputing the officially sanctioned view of what the parent-child-state relationship should be.

\section{Notes}

1. It is simply impossible to achieve any consistency for Chinese names in citation. As a general rule, in this study, full names (as known in Chinese with the surname appearing as the first name, like Deng Xiaoping rather than Xiaoping Deng) are used. This also applies to references below. For example, Wang Longlin remains Wang Longlin, unless the author uses the conventional Western way to present his or her name in English publication, in which their surname appears as the last name. For example, Lijun Bi becomes Bi, L., which appears consistent with Western names.

2. Unless otherwise specified, all translations are our own. 


\section{References}

Bernstein, R. (2011) 'Children's books, dolls, and the performance of race; or the possibility of children’s literature’, PMLA 126: 1, 160-169.

Bi, L. (2008) 'The militant trend in early patriotic works of modern Chinese children's literature', in Vicziany, A. M. \& Cribb, R. (eds) Proceedings of the 17th Biennial Conference of the ASAA, Melbourne. Available from: http://www.arts.monash.edu.au/mai/asaa/proceedings.php

Bing Xin (1926) Ji xiaoduzhe [To Young Readers]. Shanghai, Beixin shuju.

Chang, J. (1992) Wild Swans. London, HarperCollins.

Cheng Sheng (1988) Baiqizi [White Flags], in Pu Manding (ed) Zhongguo ertong wenxue daxi, xiaoshuo I, [The great anthology of Chinese Children's literature, short stories I]. Taiyuan, Xiwang chubanshe, pp. 12-17. Originally published in Weekly Review on May 26, 1919.

Cui Daoyi (1979) Duiyuan de daolu [The Road of a Young Pioneer Member], in Selected works of Shanghai children's literature, 1949-1979, vol 1. Shanghai shaonian ertong chubanshe, pp. 131-49. Originally published in 1956 in Shaonian wenyi, [Juvenile literature], no. 4, Shanghai.

Dai Pingwan (1988) Xiao Feng, in Pu Manding (ed) Zhongguo ertong wenxue daxi, xiaoshuo I, [The great anthology of Chinese children's literature, short stories I]. Taiyuan, Xiwang chubanshe, pp. 288-302. Originally published in Taiyang yuekan, May 1928.

Dreyer, J. T. (2010) China's Political System: Modernization and Tradition ( $7^{\text {th }}$ edition). New York and London, Longman.

Fairbank, J. K. (1976) The United States and China (4 ${ }^{\text {th }}$ edition). Cambridge MA and London, Harvard University Press.

Fang, X. (2003) 'Neo-Confucianism in Chinese children’s books’, Papers: Exploration into Children's Literature 13, 2, 15-26.

Gubar, M. (2009) Artful Dodgers: Preconceiving the Golden Age of Children's Literature. New York, Oxford University Press.

Legge, J. (1971) The Chinese Classics. Taipei, Wenshizhe chubanshe.

Lu Ying (1988) Liang ge xiao xuesheng [Two Pupils], in Pu Manding (ed) Zhongguo ertong wenxue daxi, xiaoshuo I, [The great anthology of Chinese children's literature, short stories I]. Taiyuan, Xiwang chubanshe, pp. 50-56. Originally published in Xiaoshuo ribao, August 1926. 
Lynch, M. (1996) China: From Empire to People’s Republic 1900-49. London, Hodder Murray.

Ma Feng (1979) Han Meimei, in Shanghai ertong wenxue xuan 1949-1979, diyijuan [Selected works of Shanghai children's literature, 1949-1979, vol 1]. Shanghai shaonian ertong chubanshe, pp. 131-49. Originally published in 1954.

Mao Zedong (1949) 'Report to the second plenary session of the seventh Central Committee of the Chinese Communist Party’, in Quotations from Chairman Mao Tse-tung (1966) Beijing, Foreign Languages Press, p. 193.

Mickenberg, J. (2006) Learning from the Left: Children's Literature, the Cold War, and Racial Politics in the United States. New York, Oxford University Press.

Reynolds, K. (2007) Radical Children's Literature: Future Visions and Aesthetic Transformations in Juvenile Fiction. New York, Palgrave Macmillan.

Rudd, D. (2004) 'Theorising and Theories: The Conditions of Possibility of Children's Literature', Hunt, P. (ed) International Companion Encyclopedia of Children's Literature ( $2^{\text {nd }}$ edition). London, Routledge, pp. 29-43.

Wang Longlin and Zhong Yanfu (eds) (1995) Huihuaben Zhongguo jingdian qimeng gushi: San zi jing, qian zi wen, dizi gui, xiaoer yu [Illustrated copies of classical Chinese enlightment stories: The three character classic, an assay of a thousand characters, rules for the young and words for children]. Beijing shaonian ertong chubanshe.

Wu Meng (ed) (1991) San zi jing, bai jia xing, qian zi wen [The three character classic, a hundred family names and an essay of a thousand characters]. Shanghai guji chubanshe.

Xin san zi jing bianxie weiyuanhui [The New Three Character Classic Compilation Committee] (1994) Xin san zi jing [The New Three Character Classic]. Guangdong jiaoyu chubanshe.

Yu Hua (1993) Zai xiyuzhong huhan [Cries in the Drizzle]. Shanghai wenyi chubanshe. Available from: http://book.kanunu.org/html/2005/0716/374.html

Xu Xu, (2011) 'Chairman Mao’s child: Sparkling Red Star and the construction of children in the Chinese Cultural Revolution’, Children’s Literature Association Quarterly 36: 4, 381-409.

\section{Biographical Notes}

Lijun Bi lectures at the School of Languages, Literatures, Cultures and Linguistics of Monash University. Her research publications are mainly on politics and ethics of Chinese children's literature. Her most recent book is China's May Fourth Poetry: Educating the Young (Common Ground, 2014). 
Xiangshu Fang is a senior lecturer at the School of Humanities and Social Sciences, Deakin University. He has published books and articles on political life in rural China, the Cultural Revolution and revival of Confucianism.

Clare Bradford is Alfred Deakin Professor at Deakin University in Melbourne. Her books include Reading Race: Aboriginality in Australian Children's Literature (2001), which won the ChLA Book Award and the IRSCL Award; Unsettling Narratives: Postcolonial Readings of Children's Literature (2007); New World Orders in Contemporary Children's Literature: Utopian Transformations (2009) (with Mallan, Stephens and McCallum); and The Middle Ages in Children's Literature (2015). From 2007 to 2011 Clare was President of the International Research Society for Children's Literature. She is a Fellow of the Australian Academy of Humanities. 